\title{
The Problems with Designing Linguistic Meanings
}

\author{
Alexey Chernyak \\ Faculty of Humanities and Social Sciences \\ Peoples' Friendship University of Russia \\ Moscow, Russia \\ E-mail: abishot2100@yandex.ru
}

\begin{abstract}
As any tool, language is created by people. Since any language which we know could be different (have different grammars, consist in different words and sounds etc.), it may be said to be designed in a certain way. Since meanings of linguistic expressions also might be different, they may be said to be designed in the past as well. But no one can design a meaning alone; this is normally a result of some collective efforts. The most popular explanation of how meanings are collectively designed by people refers to the notion of convention, but the idea of semantic convention encounters serious problems since meanings are essentially subjective and can be publicly learned neither by demonstration nor by description. As a result, the idea of semantics as conventionally designed by people looks contradictory.
\end{abstract}

Keywords-design; meaning; language; convention; coordination; function; subjectivity

\section{Meaning as a Matter OF Design}

The word "design" has several meanings. On one hand, it denotes a set of properties due to which a perception of their bearer causes certain aesthetic response. On the other hand, it often means properties which determine the appearance of an object. Also, it sometimes is used to refer to a set of properties which make their bearer functional or useful in a certain way. Thus, it may be said that pens are designed so as to provide writing when properly used. Usually, when something is said to be designed this or that way, it is presupposed that someone made it this or that way and that it could be made different. Nevertheless, it may be sometimes tempting to say about something obviously not intentionally created to serve a certain purpose that it was designed this or that way. For example, it may be said that natural selection creates a certain biological design which better serves certain needs or realizes certain functions relative to the environment the creature lives in than other possible designs the same creature could have in the same situation. It may be said that certain biological tool exists because only creatures that possessed it survived the natural selection. This happened because the tool served a useful role for those creatures in the past, and this role determines the proper or ideal function of the tool, i.e. what it is supposed or was designed to do. ${ }^{1}$ This way of talk presupposes that the very existence of a thing claimed to be designed by natural selection so as to result in certain outcomes or realize certain

\footnotetext{
${ }^{1}$ See, for example [6. P. 269], and [5. P. 168]
}

functions is determined by these outcomes or functions, that they constitute its natural teleology.

The question then is: what reasons do we have to consider such things as literally designed by force of evolution? The answer would depend on how far are we disposed to expand our notion of intentional or at least purposeful activity. Whatever the answer we choose, another claim is worth being considered: people can create artifacts designed to improve our biology. One such tool is language or actually a set of different languages, used by people for communication and thinking which without them would be available to us in much lesser degree. The most plausible hypothesis about the genesis of known languages is that they were created by people.

If words and other linguistic signs we currently use were invented by other people in the past. Then, they may be said to be also designed, although what they look like is partly constrained by human physiology and conditions of life (what sounds people's bodies may produce, and which of them, e.g., are loud enough in the current environment). Thus, in some simple case, a sound chosen to refer to a certain animal may be designed so as to represent certain sounds which this animal normally produces, i.e. imitate them. Often, what a sign looks like is determined by what it is supposed to do. Thus, a name is often chosen for a thing so as to cause certain thoughts or representations in the one who would perceive it, not necessarily representative relative to the thing itself, though. ${ }^{2}$ But further, according to Aristotle, spoken words are signs which have conventional meanings, i.e. there is no natural necessity in that certain word means certain thing or things; people decide this [1. 16a20, 16a26]. Many agree with this claim. ${ }^{3}$ If so, then meanings too are like artifacts and may be also considered as what is designed. Then, it may be said reasonable that when an expression is associated with certain meaning in order to serve certain purpose or function a specific semantic design of an expression is created.

\footnotetext{
${ }^{2}$ Thus, "New Zeeland" was supposed to remind of Zeeland rather than provide any information about the land which it names (beside, perhaps, that it was newly discovered).

${ }^{3}$ Cr.: [4], [8], [7].
} 


\section{CONVENTIONALITY AND SuBJeCtivity OF MEANINGS}

But it is clear that no one can design meanings which would fit the common purposes of communication alone; I may assign in my mind the meaning dog to the word "cat" and even use in thought "cat" to refer to dogs, but if I try to say that dogs are lazy by words "cats are lazy", I would most likely be misunderstood if my addressee didn't also assign the meaning $d o g$ to the "cat" or at least wasn't informed that I did it. Communicatively successful meanings are thus said to be designed by collective actions of different people resulting in semantic conventions.

Now the question is: how can people conventionally design meanings? The problem is that meanings are essentially subjective; we can count some things in the world as meanings of some words, but when we assign meanings, understand them, and communicate them, we use mental representations of whatever other things we want to refer to, indicate, denote, inform about, and etc. That's why, unlike the designing of, for example, a chair which an individual person may build and then demonstrate to the others and ask to be tried by them (how it fits them as a chair), the designing of a meaning may not rely in the same way on demonstrative tools. I can decide to mean $a$ by the word $x$, but I cannot demonstrate what I mean (subjectively assigned to the word) to anyone else 4 and, hence, expect that they try this meaning, how it fits them, as they would try a chair. I can say "I mean $a$ by $x$ ", but this way I would only inform that I mean by $x$ that what $a$ means for me. But what is it? I may go on by saying that by $a$ I mean so and so, but this will have the same effect: I will only say that the meaning of $a$ for me is determined by what I mean by "so-and-so" and so on ad infinitum. The addressee must already understand by "so-and-so" the same as what I mean by it in order to infer from this the proper understanding of my concept of a meaning of $x$. We believe that often when such assertions about meanings are made their addressees already have the same knowledge of meanings of explaining words as the one which the speaker has. Although this may be true, theoretically speaking, we need to explain, where this common knowledge may be taken from. And the answer is again that it is a result of conventions which were already established. Thus, some conventions are already needed in order to explain how new conventions may be generated by the use of descriptions.

Alternatively, I may use the word for which I want to design a new meaning in a certain way which could clue to the others how to assign meaning to it. That is what people also normally do when they try to teach other people to understand what they mean. But this would hardly help someone to produce the same meaning as the one which is being taught in his/her personal mind; at best, he/she would learn how to use the word by in accord with the demonstrated patterns. Some thinkers claim that meaning is use, and nothing more. ${ }^{5}$ But what is the use then? There are

\footnotetext{
${ }^{4}$ Since we cannot make our minds literally open to each other, and information contained in them directly observable.

${ }^{5}$ The most famous claim of this sort belongs to L. Wittgenstein [9. $\S 43]$.
}

at least two concepts available. First, we may understand by use just an occurrence of an item in certain circumstances. But it is too obvious that meaning is not used in this sense. A parrot may pronounce "beware", assigning no meaning to it (without any intention to communicate something by it). To be used in another sense, an item must be supplied with an intention, idea or concept of doing something with it. If I use the word with some definite intention, then what I intend to do by pronouncing this word in current circumstances may be said to be the meaning of this word's token. But this kind of meaning is again subjective. We cannot demonstrate our intentions or concepts of using the particular item directly to other people; we can only represent them by producing some behavior with more or less chances to succeed.

But the observer whom I try to show indirectly what I mean may generate in his/her mind the same meaning or concept of use as mine as a result of observing my behavior and interpreting my utterances. Why wouldn't that be then a convention between us about the meaning of the word in question? One answer may be that in such case a reproduction of a meaning was in a sense accidental; for example, it was not chosen as a result of a recursive search of a right pattern (or part of a pattern if we treat both a meaningful - intentional-utterance and its right understanding as a single pattern) which requires checking out whether the chosen meaning thus individually assigned is similar to the one it is supposed to reproduce.

\section{CONVENTION AS COORDINATION}

It is widely recognized that conventions need not be established by explicit agreements between their participants. But this does not yet exclude the necessity for subjective meanings to be made commonly known by descriptive or other means in order to be conventional. According to the most popular conception of the nature of social conventions, conventional behavior should be based on specific reasons, i.e. beliefs that other members of convention do their parts of a conventional job [3. P. 257]. In other terms, a convention is a multi-level construction constituted by common beliefs (common knowledge) shared by its participants and serving to the purpose of coordination between them. According to D. Lewis's classic representation, "a regularity $R$ in the behavior of members of a population $P$ when they are agents in a recurrent situation $S$ is a convention if and only if it is true that, and it is common knowledge in $P$ that, in any instance of $S$ among members of $P, 1)$ everyone conforms to $R, 2$ ) everyone expects everyone else to conform to $R, 3$ ) everyone prefers to conform $R$ on condition that the others do, since $S$ is a coordination problem and uniform conformity to $R$ is a coordination equilibrium in $S^{\prime \prime}$ [4. P. 58]. ${ }^{6}$

Being applied to meanings, this idea of convention as a tool of coordination presupposes that the participants of a semantic convention must have reliable evidences which would give them reasons to believe that they, and the others

\footnotetext{
6 "Coordination equilibrium" is a name for a solution of coordination problem adopted in many theories of rational choice and decision.
} 
conform to the convention by a uniform use of an expression, i.e. reproduce the conventional meaning in it. Without such reasons, any participant, according to the theory, wouldn't have motivation to prefer to conform to the convention in the future; therefore without it, the preservation of semantic conventions in time may not be explained. In order to form such reasons, members of a convention may share the beliefs with the same content part of which is the representation of a conventional meaning itself. But where such common content may come from if meanings are subjective, is unclear.

Moreover, we know that sometimes people do make explicit agreements about certain things which then may be demonstrated as being conformed or broken with. And also even when they didn't actually base a convention on an agreement we know that they, as rational agents, are capable to reestablish this convention by making an agreement. Still it is doubtful that people in the current state of human condition may literally agree about meanings, i.e. subjective stuff which they assign to the words.

Nevertheless, some thinkers assume that rational readiness to coordination, hence common knowledge, is not necessary for conventions. Thus, people may in fact coordinate their behavior without deliberately choosing to coordinate - by simply following certain rules or customs. As a result, it is claimed within that framework that the use of a natural language is based on so called natural conventions which consist just in reproducible patterns of behavior and some principles of their reproduction which generally presuppose that a pattern of behavior is conventionally reproduced by a group partially due to the weight of its precedents for the members of a group [5. P. 2, 7]. "Specific linguistic forms survive and are reproduced together with cooperative hearer responses because often enough these patterns of production and response benefit both speakers and hearers" [5. P. vi].

But a collective reproduction of a pattern requires that the pattern could be given to each of the members of the convention. If the pattern is constituted by the meaning and its understanding (both are subjective), then it just cannot be intersubjectively given. Then, the supposed members of a semantic convention may only learn from others how to reproduce the observable parts of conventional stuff which is far from learning conventional meanings. Reproduction of a pattern may be indirect, i.e. one needn't be able to copy the meaning in order to reproduce it. Perhaps, it would make sense to say that when by copying some observable part of a pattern an individual produces the rest part of it so that it happens to be similar to what was the rest part of the copied behavior, the reproduction of a whole pattern takes place. Then, it has to be concluded that natural convention may only occur if every member of a group of users of an expression $N$ somehow ends up with the same or highly similar meaning assigned to $N$ by producing what he/she supposes to be his/her part of a pattern. In this case, a coordination of subjective meanings relative to the group's use of $N$ may be in fact provided. Why not count such a result as true convention determining a semantic design of a linguistic expression? But the persons whose collective behavior constitutes this result may even not be members of the same social group. They may not cooperate and even communicate with each other in any way, and they even may speak different languages. If conventions are social, such coordination of meanings is not enough to be recognized as convention.

\section{CONCLUSION}

But there are alternative notions of convention which do not identify it with anything essentially social. Thus, according to one such account, convention is generated by any arbitrary choice of an item or a behavior among a variety of available alternatives [2]. It may be objected to this that arbitrariness itself is not essential for what we traditionally count as conventions: if arithmetic is conventional, as it seems to be, it exists in spite of the absence of functionally adequate alternatives, i.e. systems which people could use to make basic math as effective as by using arithmetic. However, if one like to count a set of individual free choices resulting by accident in coordination as a convention, who can stop him/her? But how often could such result as complete or even close similarity of subjective meanings (the coordination required for a conventional semantic design) be achieved by accidents like this? It will be eventually but not very often; it is at least not often enough to explain ordinary semantic work made by words as determined by conventions.

So, it seems that by saying that meanings are conventionally designed by people we express a contradiction however plausible the claim that people collectively use meanings is.

\section{REFERENCES}

[1] Aristotle, On Interpretation (De Interpretatione). Clarendon Aristotle Series, Oxford: Oxford University Press, 1963.

[2] R. Carnap, The Logical Syntax of Language. Chicago: Open Court Press, 2002.

[3] D. Hume, Enquiries Concerning Human Understanding and Concerning the Principles of Morals. Ed. by L. A. Selby-Brigge. Rev. 3rd edn., ed. P. H. Nidditch. Oxford: Clarendon Press, 1975.

[4] D. Lewis, Convention. Cambridge: Harvard University Press, 1969.

[5] R. Millikan, Language: A Biological Model, Clarendon Press. Oxford, 2005.

[6] D. Rose, "Three Dimensions of Psychosemantics", Gestalt Theory Vol. 34, No. 3/4, 2012, 259-286.

[7] S. Schiffer, Meaning. Oxford: Oxford University Press, 1972.

[8] J. Searle, Speech Acts. Cambridge: Cambridge University Press, 1969.

[9] L.J.J. Wittgenstein, Philosophical Investigations, ed. G.E.M. Anscombe and R. Rhees, trans. G.E.M. Anscombe, Oxford: Blackwell, 1953. 